\title{
Cilostazol Enhances Oxidative Glucose Metabolism in Both Neurons and Astroglia without Increasing Ros Production
}

\author{
Shinichi Takahashi", Yoshikane Izawa, Norihiro Suzuki \\ Department of Neurology, Keio University School of Medicine, Tokyo, Japan. \\ Email: *takashin@tka.att.ne.jp \\ R Received August $5^{\text {th }}, 2011$; revised September $13^{\text {th }}, 2011$; accepted September $25^{\text {th }}, 2011$.
}

\begin{abstract}
Cilostazol, a potent inhibitor of type 3 phosphodiesterase (PDE3), has recently been reported to exert neuroprotective effects during acute cerebral ischemic injury. These effects are, at least in part, mediated by the inhibition of oxidative cell death. However, the effects of cilostazol on glucose metabolism in brain cells have not been determined. In the present study, we examined the effects of cilostazol on the oxidative metabolism of glucose and the resultant formation of reactive oxygen species (ROS) in cultured neurons and astroglia. Cultures of neurons or astroglia were prepared from Sprague-Dawley rats. The cells were treated with cilostazol $(0-30 \mu M)$ for 48 hours prior to the assay. L- $\left[U_{-}{ }^{14} C\right]$ lactate $\left(\left[{ }^{14} C\right]\right.$ lactate $)$ or $\left[1-{ }^{14} C\right]$ pyruvate $\left(\left[{ }^{14} C\right]\right.$ pyruvate $)$ oxidation was measured. ROS production was determined using an $\mathrm{H}_{2}$ DCFDA assay with a microplate reader. Forty-eight hours of exposure to cilostazol resulted in dose-dependent increases in $\left[{ }^{14} C\right]$ lactate and $\left[{ }^{14} C\right]$ pyruvate oxidation in both the neurons and astroglia. Dibutyryl cyclic AMP $(0-0.5$ $m M)$ also increased $\left[{ }^{14} \mathrm{C}\right]$ lactate oxidation, indicating cAMP-mediated PDH activation. In contrast, free radical formation was not affected by cilostazol in either the neurons or astroglia. Cilostazol enhanced the oxidative metabolism of glucose in both neurons and astroglia, while it did not augment ROS production.
\end{abstract}

Keywords: Astrocyte, Cilostazol, Glucose, Lactate, Pyruvate Dehydrogenase

\section{Introduction}

Brain function is completely dependent on the oxidative metabolism of glucose for ATP synthesis. The functional activation of local brain lesions triggers ATP consumption by $\mathrm{Na}^{+}, \mathrm{K}^{+}$-ATPase, which restores the trans-membrane $\mathrm{Na}^{+}$and $\mathrm{K}^{+}$gradients in the local cells [1]. In contrast to the brain, the heart muscle is dependent on fatty acid oxidation in mitochondria for its energy production [2]. A type 3 phosphodiesterase (PDE3) inhibitor has been known to enhance cardiac contractile force by enhancing fatty acid metabolism [3]. Accordingly, an in vitro experiment has shown that two PDE inhibitors, enoximone and milrinone, suppress glucose oxidation in isolated cardiac myocytes [4] in accordance with Randle's hypothesis [5], implying a reciprocal control of glucose oxidation and fatty acid oxidation in living organisms. Importantly, as fatty acid is not an energy substrate for brain tissue under normal physiological conditions, the effect of PDE inhibitors on fatty acids does not affect brain energy metabolism, and the effect of PDE inhibi- tors on glucose metabolism in neural tissue has not been previously studied, as far as we know.

Cilostazol, a potent PDE3 inhibitor [6], has been used for effective secondary prevention of ischemic stroke for the past several years [7-9]. It exerts a potent antithrombotic action through the inhibition of PDE3 in both platelets and vascular endothelial cells. Unfortunately, however, the actions of cilostazol on brain parenchymal cells (i.e., neurons and glial cells) have not been examined extensively. Cilostazol also plays a neuroprotective role during acute [10] and subacute [11] phases of cerebral ischemia. This action is thought to depend on increases in the cyclic adenosine 3',5'-monophosphate (cAMP) concentration by inhibiting PDE, which, in turn, activates cAMP-dependent protein kinase (PKA) and the cAMP-responsive-element-binding protein (CREB) phosphorylation pathway, resulting in anti-apoptotic effects $[12,13]$. Moreover, cilostazol is reported to scavenge reactive oxygen species (ROS) [10]. In brain tissue, mitochondria are believed to be a main source of ROS be- 
cause oxygen consumption in the brain is high and ROS formation is further enhanced during ischemia, leading to cell death [15].

The goal of the present study was to investigate the effect of cilostazol on glucose metabolism in cultured neurons and astroglia. We also examined the effect of cilostazol on ROS production in these two types of cells.

\section{Materials and Methods}

\subsection{Animals}

Timed-pregnant Sprague-Dawley rats were purchased from Japan SLC, Inc. (Hamamatsu, Japan). All animal procedures were performed in accordance with The Animal Experimentation Guidelines of Keio University School of Medicine and were approved by the Laboratory Animal Care and Use Committee of Keio University.

\subsection{Chemicals}

Chemicals and materials were obtained from the following sources: L- $\left[\mathrm{U}_{-}{ }^{14} \mathrm{C}\right]$ lactate $\left(\left[{ }^{14} \mathrm{C}\right]\right.$ lactate; specific activity, $4.84 \mathrm{GBq} / \mathrm{mmol}),\left[1-{ }^{14} \mathrm{C}\right]$ pyruvate $\left(\left[{ }^{14} \mathrm{C}\right]\right.$ pyruvate; specific activity, $0.67 \mathrm{GBq} / \mathrm{mmol}$ ), Insta-Fluor Plus and hyamine hydroxide 10 - $\mathrm{X}$ were all obtained from PerkinElmer Life Sciences (Boston, MA, USA); Dulbecco's modified Eagle medium with or without glucose, penicillin, and streptomycin were obtained from Life Technologies (Grand Island, NY, USA); defined fetal bovine serum was obtained from HyClone Laboratories (Logan, UT, USA); trypsin-EDTA was obtained from (GibcoBRL/Invitrogen, Grand Island, NY); 2',7'-dichlorodihydrofluorescein diacetate ( $\mathrm{H}_{2}$ DCFDA) was obtained from Molecular Probe Inc. (Eugene, OR, USA); and all other chemicals were obtained from Sigma (St Louis, MO, USA). Cilostazol was a kind gift from Otsuka Pharmaceutical Co. Ltd. (Tokushima, Japan). Please do not revise any of the current designations.

\subsection{Preparation of Cells}

Primary astroglial cultures were prepared from the cerebral cortex of rat pups 24 to 48 hours after birth [16]. Approximately on day 10, the adherent cells were treated with trypsin-EDTA solution, suspended in fresh highglucose medium (diluted 1:4), and placed in uncoated 24-well culture plates (Sumitomo Bakelite, Tokyo, Japan), 12-well culture plates (Nalge Nunc International, Rochester, NY, USA), or in $25-\mathrm{cm}^{2}$ culture flasks (Nalge Nunc International). The culture medium was changed twice a week, and the cells were used once they reached confluence (days 21 to 24).

The primary neuronal culture was prepared from the forebrain of fetal rats on embryonic day 16, as described previously [16]. Assays were performed using cultures that were 7 to 10 days old. The nutrient medium remained untouched until the experiments were initiated.

Forty-eight hours before the assay, cilostazol was applied to cultured cells with or without KT5720, a potent inhibitor of PKA [17]. Cilostazol exposure was typically started on day $5-7$ for the neurons and on day $19-21$ for the astroglia. To evaluate the acute effect of cilostazol on ROS generation, some cells were grown without cilostazol; instead, cilostazol was added to the $\mathrm{H}_{2}$ DCFDA assay buffer during ROS measurement (see below).

\subsection{Measurement of the Rate of $\mathrm{L}-\left[\mathrm{U}_{-}{ }^{14} \mathrm{C}\right]$ Lactate and $\left[1-{ }^{14} \mathrm{C}\right] \mathrm{Pyruvate}$
Oxidation to ${ }^{14} \mathrm{CO}_{2}$}

The rate of $\left[{ }^{14} \mathrm{C}\right]$ lactate and $\left[{ }^{14} \mathrm{C}\right]$ pyruvate oxidation to ${ }^{14} \mathrm{CO}_{2}$ was measured using a modification of a previously described method [18]. After the cells cultured in the $25-\mathrm{cm}^{2}$ culture flasks were washed twice with phosphatebuffered saline without $\mathrm{CaCl}_{2}$ and $\mathrm{MgCl}_{2}$ (PBS), $2.5 \mathrm{~mL}$ of Dulbecco's balanced salt solution (DBSS: $110 \mathrm{mM}$ $\mathrm{NaCl}, 5.4 \mathrm{mM} \mathrm{KCl}, 1.8 \mathrm{mM} \mathrm{CaCl}_{2}, 0.8 \mathrm{mM} \mathrm{MgSO}_{4}, 0.9$ $\mathrm{mM} \mathrm{NaH} \mathrm{PO}_{4}$, and $44 \mathrm{mM} \mathrm{NaHCO}$ ) supplemented with $2 \mathrm{mM}$ of lactate and $2.5 \mu \mathrm{L}$ (approximately, $0.85 \mu \mathrm{M}$ ) of $\left[{ }^{14} \mathrm{C}\right]$ lactate (original concentration: $3.7 \mathrm{MBq} / \mathrm{mL}$ ) or 2 $\mathrm{mM}$ of pyruvate and $2.5 \mu \mathrm{L}$ (approximately, $20 \mu \mathrm{M}$ ) of $\left[{ }^{14} \mathrm{C}\right]$ pyruvate (original concentration: $18.5 \mathrm{MBq} / \mathrm{mL}$ ), which had been pre-warmed at $37^{\circ} \mathrm{C}$ and equilibrated with $7 \% \mathrm{CO}_{2}$ to adjust the $\mathrm{pH}$ to 7.4 , was added to the flasks. The culture flasks were then capped with rubber stoppers containing a center well and incubated at $37^{\circ} \mathrm{C}$ for 60 minutes. The resulting ${ }^{14} \mathrm{CO}_{2}$ was trapped by a cotton ball placed in the center well containing $100 \mu \mathrm{L}$ of hyamine hydroxide $10-\mathrm{X}$. The reactions were terminated by the injection of $250 \mu \mathrm{L}$ of $60 \%$ perchloric acid through the rubber stopper, and the flasks were kept at $4^{\circ} \mathrm{C}$ overnight to trap the ${ }^{14} \mathrm{CO}_{2}$. The center wells were transferred to $20-\mathrm{mL}$ glass scintillation counter vials, and $500 \mu \mathrm{L}$ of ethanol and $10 \mathrm{~mL}$ of Insta-Fluor Plus were added. The ${ }^{14} \mathrm{C}$ contents of the vials were then evaluated using a liquid scintillation counter.

The cell carpets left in the incubation flasks after the removal of the reaction mixtures were then digested with $5 \mathrm{~mL}$ of $0.1 \mathrm{M} \mathrm{NaOH}$, and their protein contents were determined using a bicinchoninic acid (BCA) protein assay kit (Pierce Biotechnology, Meridian Road Rockford, IL, USA) based on the use of BCA for colorimetric detection [19], according to the manufacturer's instructtions.

\subsection{Measurement of ROS Production}

The production of ROS, mainly $\mathrm{H}_{2} \mathrm{O}_{2}$, in the cells was assessed using $\mathrm{H}_{2}$ DCFDA [20] and semi-quantitative 
fluorometric measurements. Just prior to the assay, the nutrient medium was removed and the cells were washed twice with PBS without glucose. Then, DBSS containing $30 \mu \mathrm{M}$ of $\mathrm{H}_{2}$ DCFDA dissolved in dimethyl sulfoxide (DMSO) (final volume of DMSO: 0.1\%) supplemented with $2 \mathrm{mM}$ of glucose was added and the cells were incubated at $37^{\circ} \mathrm{C}$ in humidified air with $7 \% \mathrm{CO}_{2}$ for 30 minutes. After loading the cells with the $\mathrm{H}_{2}$ DCFDA, the cells were again washed twice with PBS without glucose, and DBSS containing $2 \mathrm{mM}$ of D-glucose with cilostazol was added. The cells were further incubated for up to 60 minutes, and the fluorescent level indicating intracellular ROS production was measured at 0,30 , and 60 minutes using a fluorescent microplate reader (Cytofluor $4000 \mathrm{~J}$, Applied Biosystems Japan, Tokyo, Japan) with excitation at $485 \mathrm{~nm}$ and emission at $530 \mathrm{~nm}$. As the fluorescent signals increased linearly up to $60 \mathrm{~min}$ (data not shown), the results were expressed as the percent-increase in the fluorescent signal at 60 minutes over 0 minutes. When evaluating the acute effect of cilostazol on ROS production, ROS production was measured in the presence of cilostazol in some cells that had been cultured without the addition of cilostazol.

\subsection{Statistical Analyses}

Statistical comparisons among the values obtained for each group ( $n=3$ or 4$)$ were made using grouped $t$-tests or a one-way analysis of variance (ANOVA) followed by Dunnett's test for multiple group comparisons with a single control group, when applicable. A $p$-value of $<$ 0.05 was considered statistically significant. For each experiment, at least two or three sets of assays were performed on different batches of cell preparations, and a set of representative data (mean $\pm \mathrm{SD}$ ) was presented in each figure or table.

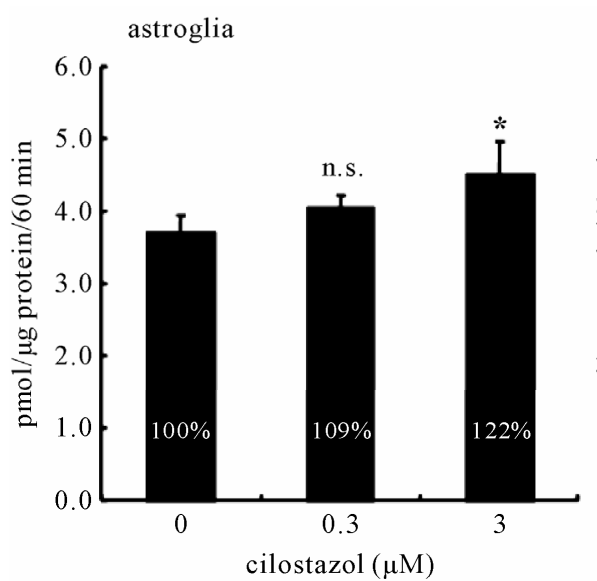

\section{Results}

\subsection{Cilostazol does Not Alter Astroglial or Neuronal Morphology}

In the present study, we chose the concentration of cilostazol according to its clinical relevance. The usual dosage of cilostazol for post-ischemic stroke patients is between 100 - $200 \mathrm{mg}$ per day, and the maximal concentration of cilostazol in plasma is approximately $2-5 \mu \mathrm{M}$ (unpublished observations by manufacturer). Therefore, we applied cilostazol at concentrations of between 0.3 $30 \mu \mathrm{M}$ in the culture medium. Dibutyryl cyclic adenosine 3', '5'-monophosphate (dbcAMP), a membrane permeable cAMP analogue $(0.5 \mathrm{mM})$, is well known to induce astroglial transformation, changing the cells from a cobblestone appearance to a fibrous shape and indicating cellular differentiation. After 48 hours of exposure to cilostazol, however, neither the astroglia nor the neurons exhibited any morphological changes, while dbcAMP $(0.5 \mathrm{mM})$ induced astroglial transformation, with the cells assumeing a fibrous shape, and indicating cellular differentiation (data not shown).

\subsection{Cilostazol Enhanced Both Lactate and Pyruvate Oxidation}

As shown in Figure 1, the rates of lactate oxidation were markedly enhanced both in neurons (right panel) and astroglia (left panel) after 48 hours of exposure to cilostazol. To confirm the enhancement of TCA cycle activity, we measured the activity of pyruvate dehydrogenase (PDH), which is a key enzyme that regulates entry to the TCA cycle by the rate of conversion of $\left[{ }^{14} \mathrm{C}\right]$ pyruvate to ${ }^{14} \mathrm{CO}_{2}$. As depicted in Figure 2, PDH activation was observed in both neurons (right panel) and astroglia (left panel) at a concentration of $3 \mu \mathrm{M}$ or over.

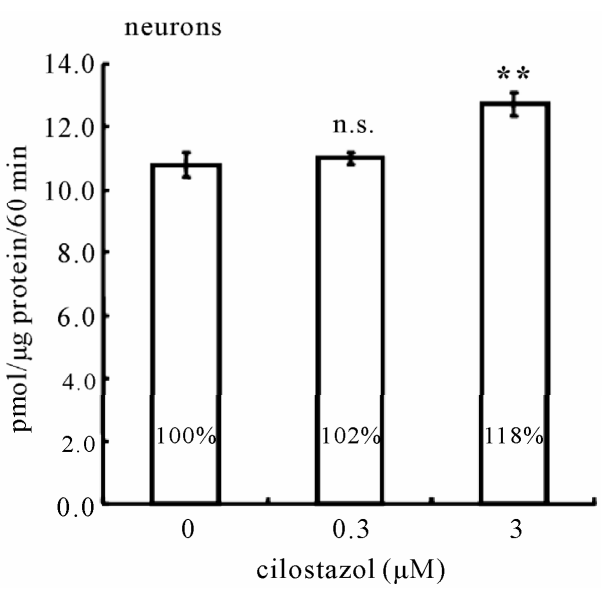

Figure 1. Effect of $48 \mathrm{~h}$ of exposure to cilostazol $(0.3-3 \mu \mathrm{M})$ on $\mathrm{L}-\left[\mathrm{U}-{ }^{14} \mathrm{C}\right]$ lactate oxidation in astroglia (left) and neurons (right). Values are the mean \pm SD of quadruplicate wells. n.s., not significant, ${ }^{*} p<0.05, * * p<0.01$ versus control (ANOVA followed by Dunnett's test for multiple comparisons). 

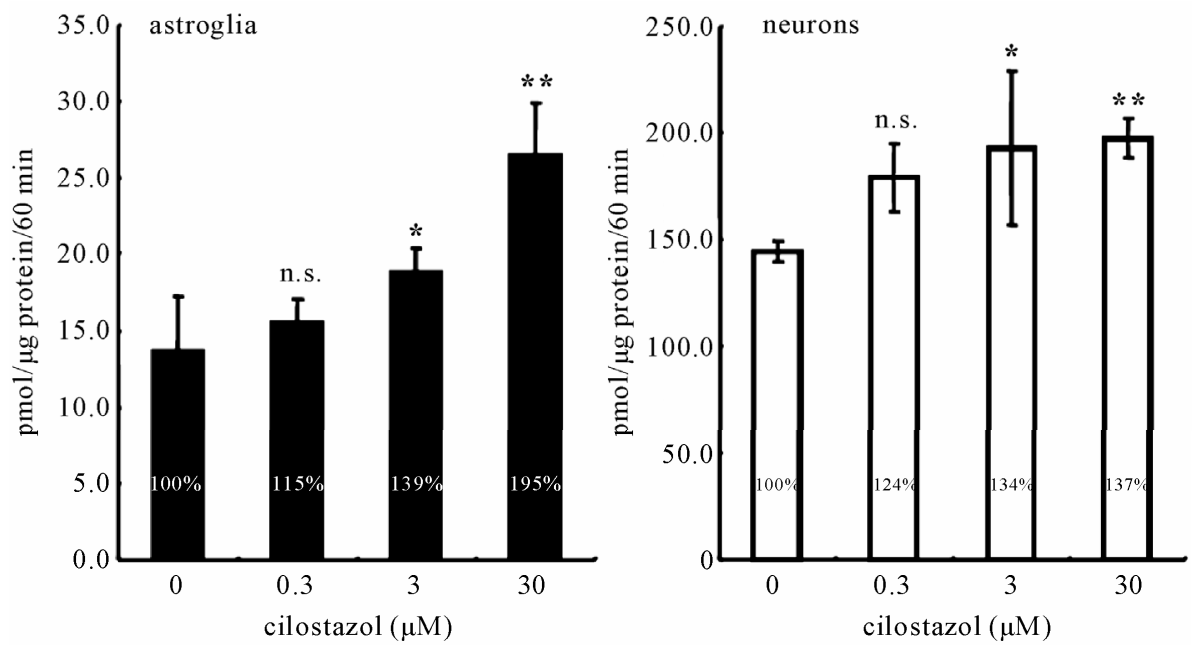

Figure 2. Effect of $48 \mathrm{~h}$ of exposure to cilostazol $(0.3-30 \mu \mathrm{M})$ on pyruvate dehydrogenase (PDH) activity, as measured by the conversion of $\left[1-{ }^{14} \mathrm{C}\right]$ pyruvate to ${ }^{14} \mathrm{CO}_{2}$ in astroglia (left) and neurons (right). Values are the mean \pm SD of quadruplicate wells. n.s., not significant, ${ }^{*} p<0.05,{ }^{* *} p<0.01$ versus control (ANOVA followed by Dunnett's test for multiple comparisons).

\subsection{Actions of Cilostazol Is Medicated by Protein Kinase a Pathway}

To explore the downstream pathway that occurs in the presence of the cilostazol-mediated enhancement of glucose metabolism, we assessed the effect of dbcAMP. dbcAMP $(0-0.5 \mathrm{mM})$ induced astroglial morphological changes (data not shown) and also increased $\left[{ }^{14} \mathrm{C}\right]$ lactate oxidation in astroglia (Figure 3), implying the involvement of cAMP. A highly specific PKA inhibitor, KT5720 $(100 \mathrm{nM})$, abolished the cilostazol-induced $(3 \mu \mathrm{M})$ increase in PDH activity in astroglia (Figure 4, left panel) and diminished that in neurons (Figure 4, right panel), indicating that cilostazol induces the oxidative metabolism of glucose through PKA-mediated PDH activation.

\subsection{ROS Production in Neurons and Astroglia Was Not Altered by Cilostazol}

Next, we evaluated whether the cilostazol-induced activation of the oxidative metabolism of glucose is associated with an augmentation of ROS production. Table 1 shows that ROS production in the neurons and astroglia was not affected, irrespective of the increased mitochondrial activity induced by incubation with cilostazol ( 0.3 $30 \mu \mathrm{M})$ for 48 hours. As cilostazol is reported to possess radical scavenging effects [10], we also evaluated the acute effect of cilostazol on ROS generation during an ROS assay. Table 1 shows that in neurons, lower concentrations of cilostazol $(0.3-3 \mu \mathrm{M})$ tended to decrease ROS production while the highest concentration $(30 \mu \mathrm{M})$ enhanced ROS production $(p<0.01$, ANOVA followed by Dunnett's $r$ test for multiple comparisons). The astroglia did not exhibit any changes in ROS production when incubated with cilostazol.

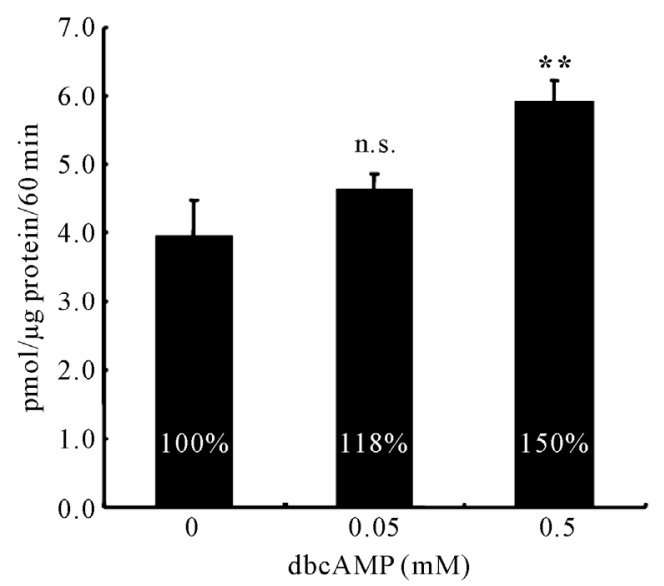

Figure 3. Effects of $48 \mathrm{~h}$ of exposure to dibutyryl cAMP $(0.05-0.5 \mathrm{mM})$ on $\mathrm{L}-\left[\mathrm{U}_{-}{ }^{14} \mathrm{C}\right]$ lactate oxidation in astroglia. Values are the mean \pm SD of quadruplicate wells. n.s., not significant, ${ }^{* *} p<0.01$ versus control (ANOVA followed by Dunnett's test for multiple comparisons).

\section{Discussion}

The present study revealed that the administration of cilostazol, a PDE3 inhibitor, at clinically relevant concentrations leads to the enhancement of the oxidative metabolism of glucose both in neurons and astroglia, implying that cilostazol may enhance ATP production in the brain and secure its function. This action of cilostazol seems to be mediated by intracellular cAMP elevation, PKA activation, and enhanced PDH activity.

cAMP is reported to enhance $\mathrm{Na}^{+}, \mathrm{K}^{+}$-ATPase activity in peripheral nerves [21], and cilostazol prevents $\mathrm{Na}^{+}, \mathrm{K}^{+}$ATPase activity from being reduced in diabetic model animals through the cAMP component [22]. Therefore, 

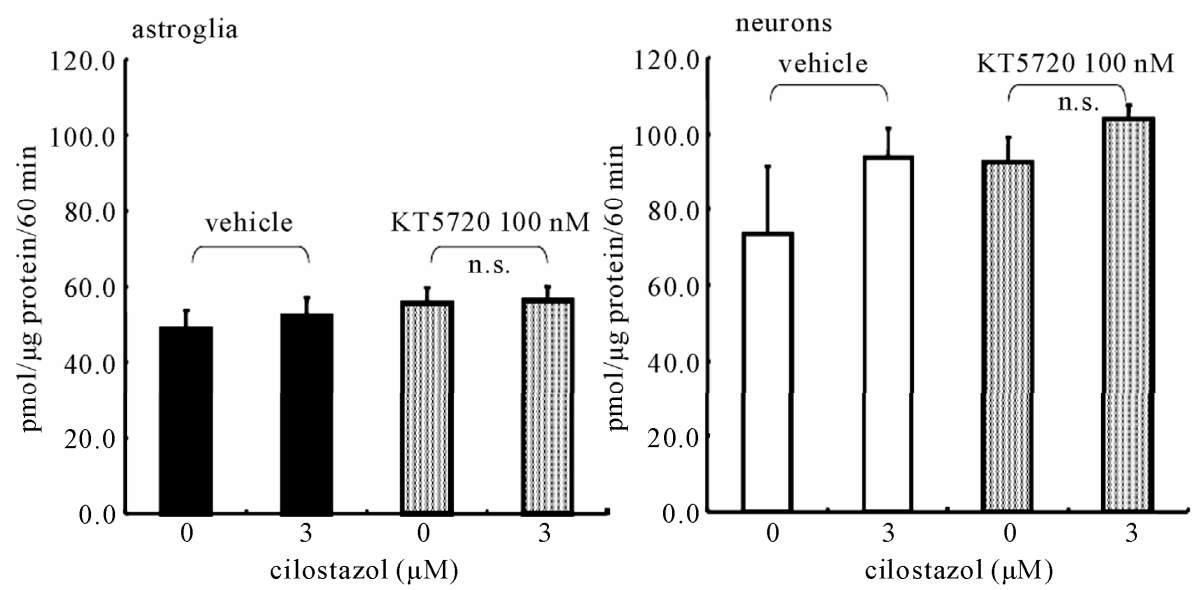

Figure 4. Effect of $48 \mathrm{~h}$ of exposure to cilostazol $(3 \mu \mathrm{M})$ on pyruvate dehydrogenase (PDH) activity ([1- ${ }^{14}$ C]pyruvate oxidation) in astroglia (left) and neurons (right) with or without exposure to a cAMPdependent protein kinase inhibitor (KT5720). Values are the mean \pm SD of quadruplicate wells. n.s., not significant (ANOVA followed by Dunnett's test for multiple comparisons).

Table 1. Effects of chronic or acute exposure to cilostazol on ROS production in astroglia and neurons.

\begin{tabular}{cccccc}
\hline & & \multicolumn{4}{c}{ Cilostazol $(\mu \mathrm{M})$} \\
\cline { 3 - 6 } & & 0 & 0.3 & 3 & 30 \\
\hline $\begin{array}{c}\text { Chronic } \\
\text { exposure }\end{array}$ & Astroglia & $43.9 \pm 2.9$ & $41.4 \pm 5.8$ & $39.8 \pm 4.7$ & $39.0 \pm 1.8$ \\
& Neurons & $55.8 \pm 3.1$ & $53.9 \pm 2.0$ & $49.2 \pm 5.0$ & $56.6 \pm 6.8$ \\
$\begin{array}{c}\text { Acute } \\
\text { exposure }\end{array}$ & Astroglia & $33.0 \pm 8.3$ & $35.3 \pm 2.7$ & $34.5 \pm 3.2$ & $32.2 \pm 2.7$ \\
\hline
\end{tabular}

cilostazol might also enhance $\mathrm{Na}^{+}, \mathrm{K}^{+}$-ATPase activity in cultured neurons and astroglia by elevating intracellular cAMP levels, leading to an enhancement in the oxidative metabolism of glucose because $\mathrm{Na}^{+}, \mathrm{K}^{+}$-ATPase consumes approximately $50 \%$ of the total ATP generated in the brain during the resting state [1]. Although we did not measure the $\mathrm{Na}^{+}, \mathrm{K}^{+}$-ATPase activity directly in the present study, our previous report showed that ouabain, an $\mathrm{Na}^{+}, \mathrm{K}^{+}$-ATPase inhibitor, reduced glucose utilization by about one half, as measured by evaluating $\left[{ }^{14} \mathrm{C}\right]$ deoxyglucose phosphorylation [16]. Therefore, cilostazol might enhance the oxidative metabolism of glucose by enhancing $\mathrm{Na}^{+}, \mathrm{K}^{+}$-ATPase activity.

The activation of $\mathrm{Na}^{+}, \mathrm{K}^{+}$-ATPase does not necessarily lead to an enhancement in the oxidation of glucose because ATP synthesis can only be provided by the enhancement of glycolysis without enhancing the oxidative metabolism of glucose. Astroglia, in particular, are more dependent on glycolysis for basal ATP production than neurons [18]. However, we observed increases in lactate oxidation in both neurons and astroglia, clearly indicating that the oxidative metabolism per se is activated and that the primary enhancement of PDH activity is an un- derlying mechanism (Figure 4). In the brain, astrocytes play important roles in glucose metabolism. Glucose supplied from brain vessels might be taken up by astrocytes and metabolized to lactate through the glycolytic pathway, even in the presence of an adequate supply of oxygen (aerobic glycolysis). Lactate is thought to be transferred to neurons and oxidized through the TCA cycle; this pathway is known as the astrocyte-neuron lactate shuttle hypothesis (ANLSH) $[23,24]$. If this hypothetical metabolic flow is correct, a simultaneous enhancement of glycolysis in astrocytes and oxidative metabolism in neurons would favor energy production in the brain as a whole. Importantly, astrocytic energy metabolism might vary between glycolytic and oxidative pathways in response to glucose environments. Under low glucose conditions, oxidative glucose metabolism in astroglia is activated and is almost comparable to that in neurons, as previously reported [18]. As a matter of fact, the astrocytic oxidative metabolism of glucose, rather than glycolysis, is reported to be essential to memory function [25,26]. Moreover, neuronal cell-specific glucose transporter-3 enables neurons to utilize glucose directly supplied from brain vessels without receiving lac- 
tate from astrocytes. Collectively, an enhancement in glucose oxidation in astrocytes might not necessarily worsen neuronal function.

The direct mechanism of the cAMP-dependent enhancement of PDH activity was not completely elucidated in the present study. PKA is a candidate enzyme that might regulate PDH activity because PKA phosphorylates various enzymes and regulates their action. PDH is regulated by PDH kinase, and the phosphorylation of PDH leads to inactivation [27-29]. As shown in Figure 4, the PKA inhibitor enhanced the basal activity of PDH in both neurons and astroglia. However, the cilostazol-mediated action was not completely abolished in neurons, whereas it completely disappeared in astroglia.

Interestingly, we found that cilostazol did not enhance ROS production in either neurons or astroglia, irrespective of the enhanced oxidative metabolism of glucose. Of course, enhancing oxidative metabolism does not necessarily cause an immediate increase in ROS production. Brain tissue possesses an active anti-oxidant system to prevent oxidative stress, and failures in this system lead to various neurodegenerative diseases [30]. Cilostazol reportedly has some action on the ROS scavenging effect [10]. In fact, acute exposure to cilostazol somehow decreased ROS production in neurons and astroglia (Table 1). The exact mechanism of this effect is unclear. PKA and the productions of ROS are interrelated [31,32]. Irrespective of the mechanism involved, cilostazol enhanced brain glucose metabolism without enhancing ROS production, which could have favorable effects on brain function.

\section{Acknowledgements}

The cilostazol used in this study was a kind gift from Otsuka Pharmaceutical Co. Ltd., Tokushima, Japan.

\section{REFERENCES}

[1] D. D. Clarke and L. Sokoloff, "Circulation and Energy Metabolism of the Brain," In: G. Siegel, B. Agranoff, R. W. Albers and S. Fisher, Ed., Basic Neurochemistry: Molecular, Cellular, and Medical Aspects, 6th Edition, Lippincott-Raven, Philadelphia, 1999, pp. 637-669.

[2] D. An and B. Rodrigues, "Role of Changes in Cardiac Metabolism in Development of Diabetic Cardiomyopathy," American Journal of Physiology: Heart and Circulatory Physiology, Vol. 291, No. 4, 2006, pp. H1489H1506. doi.org/10.1152/ajpheart.00278.2006

[3] S. Abdel-Aleem, M. Badr and C. Frangakis, "Stimulation of Fatty Acid Oxidation in Myocytes by Phosphodiesterase Inhibitors and Adenosine Analogues," Life Sciences, Vol. 48, No. 18, 1991, pp. PL97-PL102.

doi.org/10.1016/0024-3205(91)90219-2
[4] S. Abdel-Aleem, M. K. El Awadi, W. A. Zarouk, D. Taylor and J. E. Lowe, "Effects of Phosphodiesterase Inhibitors on Glucose Utilization in Isolated Cardiac Myocytes," Molecular and Cellular Biochemistry, Vol. 180, No. 1-2, 1998, pp. 129-135. doi.org/10.1023/A:1006803426578

[5] P. J. Randle, P. B. Garland, C. N. Hales and E. A. Newsholme, "The Glucose Fatty-Acid Cycle. Its Role in Insulin Sensitivity and the Metabolic Disturbances of Diabetes Mellitus," Lancet, Vol. 1, No. 7285, 1963, pp. 785789.

[6] Y. Kimura, T. Tani, T. Kanbe and K. Watanabe, "Effect of Cilostazol on Platelet Aggregation and Experimental Thrombosis," Arzneimittelforschung, Vol. 35, No. 7A, 1985, pp. 1144-1149.

[7] F. Gotoh, H. Tohgi, S. Hirai, A. Terashi, Y. Fukuuchi, E. Otomo, Y. Shinohara, E. Itoh, T. Masuda, T. Sawada, T. Yamaguchi, K. Nishimaru and Y. Ohashi, "Cilostazol Stroke Prevention Study: A Placebo-Controlled DoubleBlind Trial for Secondary Prevention of Cerebral Infarction," Journal of Stroke and Cerebrovascular Diseases, Vol. 9, No. 4, 2000, pp. 147-157.

[8] Y. Huang, Y. Cheng, J. Wu, Y. Li, E. Xu, Z. Hong, Z. Li, W. Zhang, M. Ding, X. Gao, D. Fan, J. Zeng, K. Wong, C. Lu, J. Xiao and C. Yao, "Cilostazol as an Alternative to Aspirin after Ischaemic Stroke: A Randomised, Double-Blind, Pilot Study," The Lancet Neurology, Vol. 7, No. 6, 2008, pp. 494-499.

doi.org/10.1016/S1474-4422(08)70094-2

[9] Y. Shinohara, Y. Katayama, S. Uchiyama, T. Yamaguchi, S. Handa, K. Matsuoka, Y. Ohashi, N. Tanahashi, H. Yamamoto, C. Genka, Y. Kitagawa, H. Kusuoka, K. Nishimaru, M. Tsushima, Y. Koretsune, T. Sawada and C. Hamada, "Cilostazol for Prevention of Secondary Stroke (CSPS 2): An Aspirin-Controlled, Double-Blind, Randomised Non-Inferiority Trial," The Lancet Neurology, Vol. 9, No. 10, 2010, pp. 959-968. doi.org/10.1016/S1474-4422(10)70198-8

[10] J. M. Choi, H. K. Shin, K. Y. Kim, J. H. Lee and K. W. Hong, "Neuroprotective Effect of Cilostazol against Focal Cerebral Ischemia via Antiapoptotic Action in Rats," Journal of Pharmacology and Experimental Therapeutics, Vol. 300, No. 3, 2002, pp. 787-793. doi.org/10.1124/jpet.300.3.787

[11] Y. L. Ye, W. Z. Shi, W. P. Zhang, M. L. Wang, Y. Zhou, S. H. Fang, L. Y. Liu, Q. Zhang, Y. P. Yu and E. Q. Wei, "Cilostazol, a Phosphodiesterase 3 Inhibitor, Protects Mice against Acute and Late Ischemic Brain Injuries," European Journal of Pharmacology, Vol. 557, No. 1, 2007, pp. 23-31. doi.org/10.1016/j.ejphar.2006.11.003

[12] K. W. Hong, J. H. Lee, K. Y. Kima, S. Y. Park and W. S. Lee, "Cilostazol: Therapeutic Potential against Focal Cerebral Ischemic Damage," Current Pharmaceutical Design, Vol. 12, No. 5, 2006, pp. 565-573. doi.org/10.2174/138161206775474323

[13] M. J. Kim, J. H. Lee, S. Y. Park, K. W. Hong, C. D. Kim, K. Y. Kim and W. S. Lee, "Protection from Apoptotic Cell Death by Cilostazol, Phosphodiesterase Type III In- 
hibitor, via cAMP-Dependent Protein Kinase Activation," Pharmacological Research, Vol. 54, No. 4, 2006, pp. 261267.

[14] J. H. Lee, S. Y. Park, H. K. Shin, C. D. Kim, W. S. Lee and K. W. Hong, "Protective Effects of Cilostazol against Transient Focal Cerebral Ischemia and Chronic Cerebral Hypoperfusion Injury," CNS Neuroscience \& Therapeutics, Vol. 14, No. 2, 2008, pp. 143-152. doi.org/10.1111/j.1527-3458.2008.00042.x

[15] A. Y. Abramov, A. Scorziello and M. R. Duchen, "Three Distinct Mechanisms Generate Oxygen Free Radicals in Neurons and Contribute to Cell Death during Anoxia and Reoxygenation," The Journal of Neuroscience, Vol. 27, No. 5, 2007, pp. 1129-1138. doi.org/10.1523/JNEUROSCI.4468-06.2007

[16] S. Takahashi, B. F. Driscoll, M. J. Law and L. Sokoloff, "Role of Sodium and Potassium Ions in Regulation of Glucose Metabolism in Cultured Astroglia," Proceedings of the National Academy of Sciences of the USA, Vol. 92, No. 10, 1995, pp. 4616-4620. doi.org/10.1073/pnas.92.10.4616

[17] Y. Y. Huang, K. C. Martin and E. R. Kandel, "Both Protein Kinase A and Mitogen-Activated Protein Kinase Are Required in the Amygdala for the Macromolecular Synthesis-Dependent Late Phase of Long-Term Potentiation," The Journal of Neuroscience, Vol. 20, No. 17, 2000, pp. 6317-6325.

[18] T. Abe, S. Takahashi and N. Suzuki, "Oxidative Metabolism in Cultured Rat Astroglia: Effects of Reducing the Glucose Concentration in the Culture Medium and of D-Aspartate or Potassium Stimulation," Journal of Cerebral Blood Flow \& Metabolism, Vol. 26, No. 2, 2006, pp. 153-160. doi.org/10.1038/sj.jcbfm. 9600175

[19] P. K. Smith, R. I. Krohn, G. T. Hermanson, A. K. Mallia, F. H. Gartner, M. D. Provenzano, E. K. Fujimoto, N. M. Goeke, B. J. Olson and D. C. Klenk, "Measurement of Protein Using Bicinchoninic Acid," Analytical Biochemistry, Vol. 150, No. 1, 1985, pp. 76-85. doi.org/10.1016/0003-2697(85)90442-7

[20] A. Gomes, E. Fernandes and J. L. Lima, "Fluorescence Probes Used for Detection of Reactive Oxygen Species," Journal of Biochemical and Biophysical Methods, Vol. 65, No. 2-3, 2005, pp. 45-80. doi.org/10.1016/j.jbbm.2005.10.003

[21] H. Shindo, M. Tawata and T. Onaya, "Cyclic Adenosine 3',5'-Monophosphate Enhances Sodium, Potassium-Adenosine Triphosphatase Activity in the Sciatic Nerve of Streptozotocin-Induced Diabetic Rats," Endocrinology, Vol. 132, No. 2, 1993, pp. 510-516.

[22] K. Naka, H. Sasaki, Y. Kishi, M. Furuta, T. Sanke, K. Nanjo and M. Mukoyama, "Effects of Cilostazol on Development of Experimental Diabetic Neuropathy: Functional and Structural Studies, and $\mathrm{Na}^{+}-\mathrm{K}^{+}$-ATPase Acidity in Peripheral Nerve in Rats with Streptozotocin-Induced Diabetes," Diabetes Research and Clinical Practice, Vol. 30, No. 3, pp. 153-162. doi.org/10.1016/0168-8227(95)01184-6

[23] L. Pellerin, A. K. Bouzier-Sore, A. Aubert, S. Serres, M. Merle, R. Costalat and P. J. Magistretti, "Activity-Dependent Regulation of Energy Metabolism by Astrocytes: An Update,” Glia, Vol. 55, No. 12, 2007, pp. 1251-1262.

[24] L. Pellerin and P. J. Magistretti, "Glutamate Uptake into Astrocytes Stimulates Aerobic Glycolysis: A Mechanism Coupling Neuronal Activity to Glucose Utilization," Proceedings of the National Academy of Sciences of the USA, Vol. 91, No. 22, 1994, pp. 10625-10629. doi.org/10.1073/pnas.91.22.10625

[25] M. E. Gibbs, B. S. O’Dowd, E. Hertz and L. Hertz, “Astrocytic Energy Metabolism Consolidates Memory in Young Chicks," Neuroscience, Vol. 141, No. 1, 2006, pp. 9-13.

[26] M. E. Gibbs, D. Hutchinson and L. Hertz, "Astrocytic Involvement in Learning and Memory Consolidation," Neuroscience \& Biobehavioral Reviews, Vol. 32, No. 5, 2008, pp. 927-944.

doi.org/10.1016/j.neubiorev.2008.02.001

[27] M. S. Patel and L. G. Korotchkina, "Regulation of Mammalian Pyruvate Dehydrogenase Complex by Phosphorylation: Complexity of Multiple Phosphorylation Sites and Kinases," Experimental and Molecular Medicine, Vol. 33, No. 4, 2001, pp. 191-197.

[28] M. S. Patel and L. G. Korotchkina, "Regulation of the Pyruvate Dehydrogenase Complex," Biochemical Society Transactions, Vol. 34, Part 2, 2006, pp. 217-222.

[29] M. C. Sugden and M. J. Holness, "Recent Advances in Mechanisms Regulating Glucose Oxidation at the Level of the Pyruvate Dehydrogenase Complex by PDKs," American Journal of Physiology: Endocrinology and Metabolism, Vol. 284, No. 5, 2003, pp. E855-E862.

[30] A. Reynolds, C. Laurie, R. L. Mosley and H. E. Gendelman, "Oxidative Stress and the Pathogenesis of Neurodegenerative Disorders," International Review of Neurobiology, Vol. 82, 2007, pp. 297-325. doi.org/10.1016/S0074-7742(07)82016-2

[31] N. Koike, T. Takamura and S. Kaneko, "Induction of Reactive Oxygen Species from Isolated Rat Glomeruli by Protein Kinase C Activation and TNF-Alpha Stimulation, and Effects of a Phosphodiesterase Inhibitor," Life Sciences, Vol. 80, No. 18, 2007, pp. 1721-1728. doi.org/10.1016/j.lfs.2007.02.001

[32] S. Raha, A. T. Myint, L. Johnstone and B. H. Robinson, "Control of Oxygen Free Radical Formation from Mitochondrial Complex I: Roles for Protein Kinase A and Pyruvate Dehydrogenase Kinase," Free Radical Biology \& Medicine, Vol. 32, No. 5, 2002, pp. 421-430. doi.org/10.1016/S0891-5849(01)00816-4 